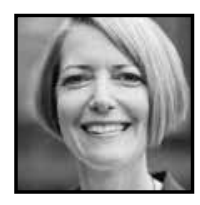

\title{
Understanding Inquiry as Stance: Illustration and Analysis of One Teacher Researcher's Work
}

\author{
Nancy Fichtman Dana, University of Florida
}

\begin{abstract}
The development of "inquiry as stance" is a foundational component of the teacher research movement. Yet, it is difficult to exemplify this construct to gain insights into its meaning and what it might look like in practice. The purpose of this article is to initiate discussion about the construct of stance through the provision and analysis of an eight-minute video clip depicting one teacher researcher's work. Three components of stance are discussed in relationship to the video example: (1) Data Collection as a Part of Teaching, (2) Roles of Inquirer and Teacher Blend Seamlessly With One Another, and (3) Commitment to the Creation of More Equitable Classrooms.
\end{abstract}

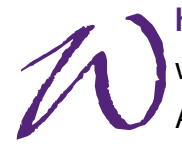

hen I became a classroom teacher in the 1980s, I was immediately inundated with messages about the profession I had entered that troubled me greatly. As a teacher, I was supposed to follow the teacher's manual and do as I was told to do. In addition, I was kept overwhelmingly busy with paperwork and other tasks that diverted my focus away from the core work I had been hired to do-understand and teach each learner I was responsible for that school year. It didn't take long for me to discover that the culture of teaching was not at all as I had imagined it to be all the years I had longed to study teaching at the university and begin my career as an educator. Rather than teaching being an intellectual pursuit where one is empowered to make instructional decisions based on one's knowledge of the students coupled with one's knowledge of the field, I was preoccupied with daily survival in conditions that were often not conducive for me to meet the learning needs of every child. 
Using a comparison between teachers and peasants within a Third World culture with hierarchical power structures, scarce resources, and traditional values, Kincheloe's (1991) writing in his book, Teachers and Researchers: Qualitative Research as a Path to Empowerment, captured my early career experiences in teaching perfectly:

Like their third world counterparts, teachers are preoccupied with daily survival time for reflection and analysis seems remote and even quite fatuous given the crisis management atmosphere and the immediate attention survival necessitates. In such a climate those who would suggest that more time and resources be delegated to reflective and growth-inducing pursuits are viewed as impractical visionaries devoid of common sense. Thus, the status quo is perpetuated, the endless cycle of underdevelopment rolls on with its peasant culture of low morale and teachers as 'reactors' to daily emergencies. (p. 12)

Disheartened and discouraged by the culture of teaching I found myself immersed in so elequently described by Kincheloe, I left the classroom after four years of teaching to pursue doctoral studies with the hope of being better positioned in higher education to change the culture of teaching I had been living as a classroom teacher, and during that time, was fortunate to find the process of teacher research.

During my graduate studies, I learned that the concept "teachers as researchers" had been around for decades, tracing its roots to the work of John Dewey (1933), popularized by Kurt Lewin in the 1940s (Adelman, 1993), and shortly thereafter applied to the field of education by Stephen Corey (1953). The term "teachers as researchers" refers to the systematic and intentional study by teachers of their own classroom practice. As I read about, tried, studied, and learned more and more about the process as a doctoral student, I was hooked. Indeed, teachers researching their own practice could be a powerful mechanism to contribute to the transformation of the teaching profession itself. I was once again inspired by the words of Kincheloe (1991): "The plethora of small changes made by critical teacher researchers around the world in individual classrooms may bring about far more authentic educational reform than the grandiose policies formulated in state or national capitals" (p. 14).

Having been sold during my graduate studies on the potential teacher research holds for transforming the profession of teaching, I have been engaging in, teaching about, coaching, and studying the process ever since. Multiple models, iterations, and even names for the process (i.e., "teacher research," "action research," "classroom research," "practitioner inquiry," "teacher inquiry," "teacher self-study") have emerged through the years and have been actualized in varying ways for varying purposes 
(Somekh \& Zeichner, 2009). In my own work, I have defined this practice as teachers' engagement in a cyclical process of posing questions or "wonderings," collecting data to gain insights into wonderings, analyzing the data along with reading relevant literature, taking action to make changes in practice based on new understandings developed during inquiry, and sharing findings with others (Dana \& Yendol-Hoppey, 2014; Dana, 2013). I have found this model of inquiry to be particularly useful to scaffold powerful job-embedded learning for educators (Yendol-Hoppey \& Dana, 2010; Dana, Thomas, \& Boynton, 2011; Dana, 2009) as well as support the learning of new teachers as they prepare to enter the profession (Dana, Silva, \& Snow-Gerono, 2002; Dana \& Silva, 2001).

Yet in over 20 years of work developing this model though inquiring into my own teaching practice and scaffolding other educators in the process as well, I have been haunted by a tension in teacher research. To provide entrée to the process, I break teacher research down into its component parts and take teachers through each part one step at a time:

(1) Develop a wondering, a burning question you have about practice;

(2) Develop a data collection plan to gain insights into your wondering;

(3) Collect and analyze data;

(4) Synthesize your learning and share with others through presentation and/or writing; and

(5) Take action for change based on what you have learned.

While simplifying the process by breaking it down into its component parts helps teachers access and learn how to study one's own practice, the breaking down of the process into its component parts can also result in teachers experiencing a feeling of finality, like they have come to the end of a long journey after they have completed "the last step." Therefore, teachers may begin to view inquiry as a linear process, and focus on the outcome, the ending of one project, one exploration, one wondering, ... and then go back to the act of teaching, and "business as usual." As a linear project, teacher inquiry is not a part of teaching, it is apart from it.

If teacher inquiry remains apart from teaching rather than becoming a part of teaching, it has limited potential to transform the profession of teaching in the ways Kincheloe discusses in his writing. A teacher researching her own practice is not about the doing of a teacher research project that is completed at one point in time and is over. Rather, teacher inquiry is a continual cycle that all educators spiral through throughout their professional lifetimes - a professional positioning or stance, owned by the teacher, 
where questioning, systematically studying, and subsequently improving one's own practice becomes a necessary and natural part of a teacher's work.

\section{Inquiry as Stance Versus Inquiry as Project}

The term "inquiry as stance" was first coined by Marilyn Cochran-Smith and Susan Lytle. When these scholars first began writing about inquiry as stance in the late $90 \mathrm{~s}$, they described it as follows:

In everyday language, "stance" is used to describe body postures, particularly with regard to the position of the feet, as in sports or dance, and also to describe political positions, particularly their consistency (or lack thereof) over time. . . In our work, we offer the term inquiry as stance to describe the positions teachers and others who work together in inquiry communities take toward knowledge and its relationships to practice. We use the metaphor of stance to suggest both orientational and positional ideas, to carry allusions to the physical placing of the body a well as to intellectual activities and perspectives over time. In this sense the metaphor is intended to capture the ways we stand, the ways we see, and the lenses we see through. Teaching is a complex activity that occurs within webs of social, historical, cultural, and political significance. Across the life span, an inquiry stance provides a kind of grounding within the changing cultures of school reform and competing political agendas. (Cochran-Smith \& Lytle, 1999, pp. 288-289)

Since then, Cochran-Smith and Lytle (2009) have authored an entire book entitled Inquiry as Stance, carefully choosing these words for their title to suggest that inquiry is more than the sum of its parts (developing questions, collecting and analyzing data, making one's study public, and taking actions for change based on what was learned through the process). Rather, inquiry is

a worldview and a habit of mind-a way of knowing and being in the world of educational practice that carries across educational contexts and various points in one's professional career and that links individuals to larger groups, and social movements intended to challenge the inequities perpetuated by the educational status quo. (p. vii)

This is the essence of inquiry as stance. I believe this is why one engages in the process of inquiry in the first place. It is a way to live one's life as an educator to maximize 
impact, making life and learning conditions better for all the children we teach. It is a way to transform the profession of teaching from the ways Kincheloe described it in his writing and I experienced it as classroom teacher.

Yet, as previously mentioned, tension exists between inquiry stance (one's way of being as a teacher) and progressing through all the steps of the inquiry process to produce a piece of teacher research. But which comes first, the adoption of an inquiry stance towards teaching or the production of teacher research projects? The posing of this question resembles the old adage, "Which comes first, the chicken or the egg?" It might be logical to think that stance comes first, but I have seen many teacher researchers approach the teacher research process first as a project they were required to complete to earn professional development points for state licensure or a new professional development initiative their school or district is trying (veteran teachers), or as a "university thing" —an assignment they had to complete for a college course (prospective teachers). While they initially approached their work as project, it was through the completion of the project that they developed stance. While it is possible that engagement in inquiry as a project can lead to the development of inquiry as a stance, there is no guarantee that this will occur. Therefore, it's important to raise this tension and explore it.

Several collections of teacher researchers' reports on their work illustrate the ways the concept inquiry as project might look like in practice (see, for example, Caro-Bruce, Flessner, Klehr, \& Zeichner, 2007; Meyers \& Rust, 2003; Brindley \& Crocco, 2009; Perry, Henderson, \& Meier, 2012). However, it is more difficult to find illustrations of inquiry as stance in practice-what it looks like and what it means to approach inquiry as a way of being and teaching. In an initial attempt to capture inquiry as stance, I created a short video clip that captures the story of teacher researcher Stephanie Whitaker, and the ways she approaches her work as a teacher inquirer.

\section{Inquiry as Stance: An Illustration}

In an effort to become a better teacher of English Language Learners and improve their achievement in mathematics, Stephanie Whitaker read numerous research studies in mathematics education that pointed to the importance of teaching mathematics for conceptual understanding, rather than teaching procedure only. With this research base in mind, she worked to transform her teaching of mathematics to ESOL (English for Speakers of Other Languages) students through engagement in teacher inquiry, 
using the data she generated from her classroom-based research as practice-based evidence for the moves she made as a teacher, including when and how to question students' conceptual understanding of the mathematics constructs she teaches. Following the video, Stephanie's story is analyzed to reveal three components of critical importance in relationship to the development of inquiry as stance.

\section{Click on Link Below For Video}

http://www.kaltura.com/tiny/wtp31

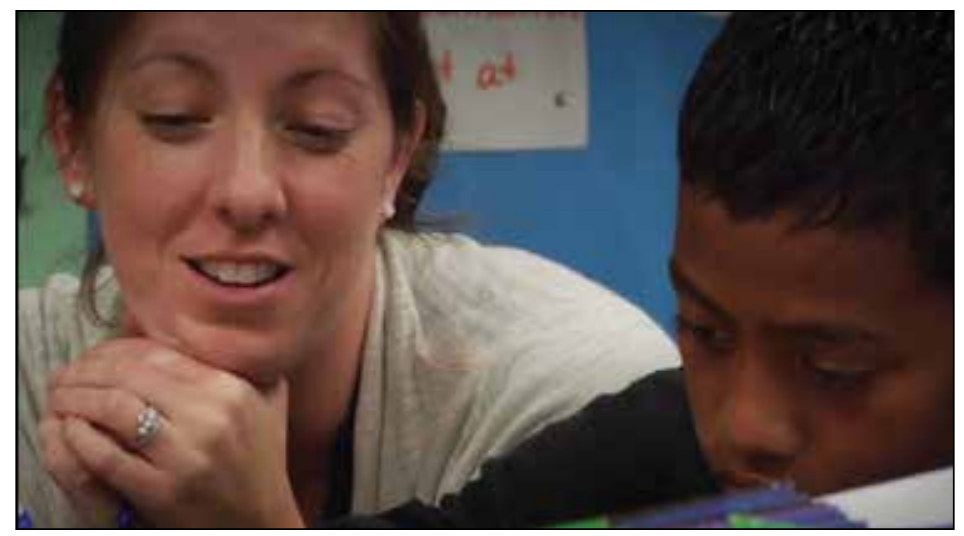

\section{Inquiry as Stance: Analysis of Illustration}

While the illustration of inquiry and how it might play out in practice that is depicted in the short video clip shared above is incomplete (in this short video, we aren't actually able to see, critique, and analyze each component of Stephanie's research), it does bring visibility to three important components of the construct "inquiry as stance." These three components include:

1. The data collection for Stephanie's inquiry takes place as a part of her teaching, rather than apart from her teaching;

2. Stephanie's role as an inquirer and Stephanie's role as a teacher become seamlessly blended and integrated with one another; and 
3. An underlying premise of Stephanie's inquiry is to create more equitable learning conditions for all by closing the mathematics learning achievement gap for her ESOL students.

\section{Inquiry Stance Component \#1: Data Collection as a Part of Teaching}

Teacher researchers collect data using many different mechanisms including observations, student work, digital pictures, video, reflective journals, weblogs, surveys, quantitative measures of student achievement, critical friend group feedback, and literature (Dana \& Yendol-Hoppey, 2014). Some forms of data, such as observations and student work, closely connect to and are easily associated with the natural and normal acts of teaching and learning that occur in the classroom on a daily basis. Other forms of data collection, however, are sometime layered "on top of" the natural and normal acts of teaching. For example, a teacher researcher might schedule a time after school to interview a student or a group of students about their learning and how it relates to the teacher's research question, following an interview protocol developed prior to the event. In this case, the "interview" is viewed as a formal process and gets layered on top of daily classroom activity and routine.

When a teacher approaches inquiry as stance rather than inquiry as project, data collection becomes more and more a part of the natural and normal acts of teaching and less and less layered on top of daily classroom activity and routine. In Stephanie's case, she conducted an interview of Stoudamire as a natural part of her lesson and instructional activities. Furthermore, she collected data on all learners in her classroom as it was generated naturally and normally during the regular acts of teaching and learning. Stephanie viewed data collection not as an "add on" to what she does in the normal everyday act of teaching, but merely as an extension of what she does in the normal everyday act of teaching. Data collection became a part of, rather than apart from, her ordinary teaching practice.

\section{Inquiry Stance Component \#2: Roles of Inquirer and Teacher Blend Seamlessly With One Another}

Research and teaching are generally conceptualized as two separate entities. A commonly held belief is that the role one plays as a teacher must remain separate and distinct from the role one plays as a researcher so as not to influence or "contaminate" research findings. 
When a teacher approaches inquiry as stance rather than inquiry as project, the role of teacher and the role of researcher become seamlessly integrated with one another. Marilyn Cochran-Smith and Susan Lytle (2009) call this important interplay "working the dialectic":

The term dialectic refers to the tensions and presumed contradictions between a number of key ideas and issues that have to do with research, practice, and knowledge. The first, and perhaps most important of these, is the assumed dichotomy between research and practice; the second is the twin of the first - the assumed disjuncture between the role of the researcher and the role of the practitioner. When research and practice are assumed to be dichotomous, then analysis, inquiry, and theorizing are understood to be part and parcel of the world of research, while action, experience, and doing are considered integral to the world of practice.

In contrast, practitioner research is defined, at least in part, by turning these dichotomies on their heads. With practitioner research, the borders between inquiry and practice are crossed, and the boundaries between being a researcher and being a practitioner are blurred. Instead of being regarded as oppositional constructs, then inquiry and practice are assumed to be related to each other in terms of productive and generative tensions. From this perspective, inquiry and practice are understood to have a reciprocal, recursive, and symbiotic relationship, and it is assumed that it is not only possible, but indeed beneficial, to take on simultaneously the roles of both researcher and practitioner. This means that when school-based educators "work the dialectic" of inquiry and practice, there are not distinct moments when they are only researchers or only practitioner. Rather, these activities and roles are integrated and dynamic. (pp. 93-95).

In Stephanie's case, who Stephanie is as a teacher and who Stephanie is as an inquirer are challenging to distinguish from one another in the video clip. As she interviews Stoudamire, Stephanie is both researcher and teacher. As researcher, Stephanie is systematically and intentionally exploring how she can help ESOL students develop conceptual understanding of mathematics. As teacher, Stephanie is processing Stoudamire's understanding of fraction denominators to make instructional decisions about where to go next in her teaching of this concept to this individual learner as well as to her whole class. Furthermore, as teacher, Stephanie uses her interview with Stoudamire as a teaching tool during whole class instruction to review the meaning of denominators in relationship to constructing models of fractions. As Cochran-Smith and Lytle state, there are no distinct moments in Stephanie's interview of Stoudamire where she is only researcher or only teacher. Rather, she occupies these roles simultaneously, 
"working the dialectic" of inquiry and practice, and illustrating a second component of inquiry as stance.

\section{Inquiry Stance Component \#3: Commitment to the Creation of More Equitable Classrooms}

While not explicitly stated in the video, Stephanie teaches a class of learners whose first language is not English. Oftentimes in the United States, these learners can be marginalized and lost in the traditional school system. Stephanie has made a commitment to help these learners thrive in a system that often fails to create equitable learning opportunities for English Language Learners. Rather than be satisfied with lower than average scores on mathematics assessments because her learners are not native English speakers, Stephanie's inquiry focuses on ways to close the achievement gap between her learners and others in her school by teaching mathematics conceptually rather than just procedurally as she has done in the past. Stephanie makes this pursuit the target of her own professional development as a teacher as she learns with and from her ESOL students about teaching mathematics conceptually and the impact such teaching can have on student learning through engagement in inquiry.

According to Cochran-Smith and Lytle (2001):

a legitimate and essential purpose of professional development is the development of an inquiry stance on teaching that is critical and transformative, a stance linked not only to high standards for the learning of all students but also to social change and social justice and to the individual and collective professional growth of teachers. (p. 46)

Cultivating an inquiry stance toward teaching means making a commitment to continuing one's professional growth throughout the professional lifetime that is led by a simultaneous commitment to high standards for all students. Stephanie's video provides a glimpse into what that commitment might look like in practice.

\section{Conclusions}

The purpose of this piece was to explore the notion of inquiry stance in relationship to the teacher research movement, and the tension that exists within the movement between inquiry as project and inquiry as stance. While numerous examples of inquiry 
as project abound through the publication of a plethora of teachers' reports of their research, it is much more difficult to exemplify inquiry as stance, what this construct means, and what it might look like in practice. Yet, this construct is essential to fulfilling the underlying aims for the teacher research movement.

By constructing and analyzing a video clip of one teacher researcher's work in relationship to inquiry stance, I have attempted to provide the beginnings of a way to exemplify this construct, providing a small glimpse into the ways this construct might look like and play out in the everyday work of a teacher researcher. While an eight-minute video representation of the complexity of a teacher researcher's work admittedly falls short to do justice to the concepts of both inquiry as project and inquiry as stance, my hope is this video representation will spur continued dialogue and debate about the relationship between progressing through all the steps of the inquiry process to produce a piece of teacher research (inquiry as project) and the development of inquiry as a stance, a habit of mind and way of being in the profession of teaching. By making the construct of stance more explicit, I believe there is greater chance and opportunity for teachers to develop stance as a result of their completion of an inquiry project. As a result, the teacher researcher community will be strengthened and grow, and there is greater possibility to change the culture of teaching from the one Kincheloe (1991) describes as containing hierarchical power structures, scarce resources, and traditional values that serve to silence the voice of the teacher to a culture containing rich opportunities for teachers to engage in the intellectual pursuit of teaching, having a clear voice in their work as they learn with and from their students and take informed action to make life and learning conditions better for all.

\section{References}

Adelman, C. (1993). Kurt Lewin and the origins of action research. Educational Action Research, 1(1), 7-24.

Brindley, R., \& Crocco, C. (2009). Empowering the voice of the teacher researcher: Achieving success through a culture of inquiry. New York: Rowman \& Littlefield.

Caro-Bruce, C., Flessner, R., Klehr, M., \& Zeichner, K. (2007). Creating equitable classrooms through action research. Thousand Oaks, CA: Corwin.
Cochran-Smith, M., \& Lytle, S. L. (1999). Relationships of knowledge and practice: Teacher learning in communities. Review of Research in Education, 24, 249-305.

Cochran-Smith, M., \& Lytle, S. L. (2001). Beyond certainty: Taking an inquiry stance on practice. In A. Lieberman \& L. Miller (Eds.), Teachers caught in the action: Professional development that matters (pp. 45-58). New York: Teachers College Press. 
Cochran-Smith, M., \& Lytle, S. L. (2009). Inquiry as stance: Practitioner research for the next generation. New York: Teachers College Press.

Corey, S. M. (1953). Action research to improve school practice. New York: Teachers College Press.

Dana, N. F. (2009). Leading with passion and knowledge: The principal as action researcher. Thousand Oaks, California: Corwin Press.

Dana, N. F. (2013). Digging deeper into action research: $A$ teacher inquirer's field guide. Thousand Oaks, CA: Corwin Press.

Dana, N. F., \& Silva, D. Y. (2001). Student teachers as researchers: Developing an inquiry stance towards teaching. In J. Rainer \& E. M. Guyton (Eds.). Research on the Effects of Teacher Education on Teacher Performance: Teacher Education Yearbook IX, (pp. 91-104). New York: Kendall-Hunt Press.

Dana, N. F., Silva, D. Y., \& Snow-Gerono, J. (2002). Building a culture of inquiry in professional development schools. Teacher Education and Practice, 15(4), 71-89.

Dana, N. F., Thomas, C., \& Boynton, S. (2011). Inquiry: A districtwide approach to staff and student learning. Thousand Oaks, CA: Corwin Press.
Dana, N. F., \& Yendol-Hoppey, D. (2014). The reflective educator's guide to classroom research: Learning to teach and teaching to learn through practitioner inquiry, 3rd Edition. Thousand Oaks, California: Corwin Press.

Dewey, J. (1933). Democracy and education. New York: Free Company.

Kincheloe, J. (1991). Teachers as researchers: Qualitative inquiry as a path to empowerment. New York: Falmer.

Meyers, E., \& Rust, F. (Eds.). (2003). Taking action with teacher research. Portsmouth, $\mathrm{NH}$ : Heinemann.

Perry, G., Henderson, B., \& Meier, D. R. (2012). Our inquiry, our practice: Undertaking, supporting, and learning from early childhood teacher research(ers). Washington, DC: National Association for the Education of Young Children.

Somekh, B., \& Zeichner, K. (2009). Action research for educational reform: Remodeling action research theories and practices in local contexts. Educational Action Research, 17(1), 5-21.

Yendol-Hoppey, D., \& Dana, N. F. (2010). Powerful professional development: Building expertise within the four walls of your school. Thousand Oaks, California: Corwin Press.

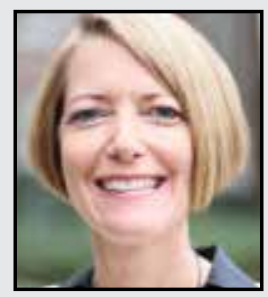

Nancy Fichtman Dana is Professor of Education in the School of Teaching and Learning at the University of Florida. Since earning her PhD from Florida State University in 1991, she has been a passionate advocate for teacher inquiry in her appointments as a faculty member at both the Pennsylvania State University and the University of Florida. She has worked with numerous schools and districts across the United States and abroad to craft professional development programs of inquiry as well as conducted extensive research on the process, publishing nine books and over 60 articles and book chapters on the topic. 